Training

\section{Academic paediatrics}

\section{T Weaver}

\section{Crisis or opportunity?}

$\checkmark t$ here has been a perception for some time that "academic paediatrics" is in a state of crisis. ${ }^{1}$ University departments of paediatrics (child health, child life, etc) have been disappearing, some fusing with other departments and others absorbed into divisions, schools, or larger entities. Loss of clinical lecturers has been one consequence, as universities make high quality research their priority. The warning is raised that if academic departments vanish, the future leaders of paediatrics will be lost. ${ }^{2}$ What is happening to academic paediatrics is not unique, but paediatricians have been surprised and distressed by it. Just when our new Royal College unites the specialty and gives it a stronger identity, we find the universities trying to do away with our academic departments. This has resulted in anguish, wringing of hands, and even shroud waving.

There are a number of reasons for this "crisis". The demands of the research assessment exercise (RAE), the physical dislocation of "science" departments from clinical sites, and the drive by universities to concentrate on income generation through research to the neglect of the health problems of children, and undergraduate teaching, have impacted on academic staffing. ${ }^{2}$ The pressures generated by shorter specialist training, consequent on "Calmanisation", European training, and working hours directives, discourage young doctors from pursuing an academic career. The "new" student centred, problem based undergraduate curricula fail to equip medical students for a career in research. The lack of systematic teaching in the basic sciences is in part rectified by intercalated BSc courses, but most medical graduates have a weak grounding in the sciences that underpin modern clinical medicine. This has to be acquired post-graduation, and few young doctors experience research during their early clinical training.

\section{BIOLOGY AND PATHOLOGY OF EARLY LIFE}

Paediatricians have a proud and productive history of collaboration with nonclinical scientists, such as in neonatology, neuroscience, and nutrition. In vaccine development and imaging, for example, they have been at the forefront, sharing in prestigious prizes and FRSs. The big questions in child health may have changed, but are clear enough: the early origins of health and disease, the genetic and molecular basis of conditions manifest first in infancy and childhood, and the aetiology, prevention, and treatment of specific childhood diseases. ${ }^{3}$ Modern medicine is increasingly applied biology and technology, and in a global research environment there are rich opportunities for fruitful collaborations, and plenty of funding. We need clinical scientists that are trained in appropriate scientific methods and understand the nature of childhood development and disease. They must be comfortable at bench and bedside.

There has long been a tension between the demands of "doing science" and "practising medicine" within those who choose to combine them. ${ }^{4}$ In the past it may have been possible for young paediatricians to learn to be clinical investigators or even laboratory based scientists, after their medical training. The old fashioned model of discrete departments, single handed clinical investigators, working alone or with little support in a clinical environment, has been replaced by interdisciplinary teams of researchers (some clinical, some non-clinical) using modern techniques, resourced to address big scientific questions effectively and efficiently, sometimes remote from a clinical base. Small departments in many universities have been slow and poorly equipped to react. Collaboration and critical mass is the name of the game. The changes that have come about over the last decade are not a process of disintegration, but of mould breaking. A new form of training that is more systematic and purposeful is demanded now, dictated by the nature of modern scientific methodology. The Academy of Medical Sciences has been a voice of the Royal Colleges and universities in debating these issues. ${ }^{5}$ The recent report "Modernising Medical Careers" ${ }^{\prime 6}$ now articulates them further, with stronger focus on the NHS and its role. A number of proposals are made, including integrated clinical pathways for training medical academics.

\section{WHAT SHOULD WE DO?}

We cannot and should not train future academic paediatricians exclusively in departments of paediatrics, unless they have a close and mutually supportive relationship with non-clinical scientific departments or research groups. The new academic training pathways offer the means, during the foundation years and in specialist training. ${ }^{6}$ We must establish clinician scientist trainees in multidisciplinary research groups within or allied to university researchers (for example, molecular, epidemiology, etc). This requires "letting go" of them, "embedding" them in research groups where they will acquire a scientific training in methods relevant to clinical questions, and then "bringing them back" into paediatrics. The onus is on academic paediatricians to establish cognate research groups within the portfolios of university research themes/divisions, which in large part are defined by their potential to succeed in the RAE. The onus is on the RCPCH and new postgraduate medical education training board (PMETB) to develop flexible competence based systems of assessment that accommodate the dual training of clinician scientists.

The dominance of molecular biology and the "new genetics" to medical research is waning as the challenge of understanding their relevance and implications, and applying novel findings to physiological and metabolic processes gets underway. The tide is turning in favour of "clinical", whole body research, and intervention trials. This is being facilitated by the recognition of the potential of the health service to conduct large clinical trials, and convergence of NHS R\&D agendas with those of university based clinical researchers. The testing of children's medicines and vaccine development are welcome examples of new collaborative initiatives combining complementary expertise within clinical research facilities. Such partnerships between the universities and health service may also rationalise responsibilities and resources for undergraduate medical teaching.

\section{SEIZE THE OPPORTUNITIES}

Paediatrics is securely established as an independent medical specialty, with its own royal college. Preoccupation with the pressing issues of training, continuing professional development, revalidation, and governance should not lead to introspection. Paediatricians must not regard their calling as too holy or pure a vocation and forget that child health is the basis of adult health. They have not led the way in re-establishing this vital connection. ${ }^{3}$ To advance world class research into subjects that will benefit 
both children and adults, they should get into bed with geneticists, epidemiologists, fetal medicine specialists, and "basic scientists" in molecular biology, immunology, neuroscience, pharmacology, medical physics, and nutrition, among other subjects. They can afford to relax their defence of the independent, special status of paediatrics, and embrace their colleagues in these related specialties in sharing the common goal of researching major questions that determine early health and affect the natural history of disease throughout life.

The "crisis in academic paediatrics" may be perceived as a threat to departments of child health. But it is not a threat to child health itself. Crossing the boundaries that surround paediatrics and separate it from other allied specialties, and forging alliances with them in the common interest in research into the biology, pathology, and public health of early life must be the future.
The opportunities for funding are there; new models for the training of aspiring clinical researchers, and for postdoctoral support are emerging. ${ }^{7}$ European and global research networks are easily established, through email and cheap travel. Facilitated by the EU, specialist medical societies, and industry, the "added value" of sharing expertise, pooling patients, and interchanging trainees can be exploited. In this respect Europe may be ahead of North America. The old mould is broken. The new structures will reinvigorate paediatrics through cross fertilisation and put it at the heart of research into the early genesis of adult ill health, the developmental basis of rare congenital disease, and many common heath problems.

\section{ACKNOWLEDGEMENTS}

Thanks are extended to Prof. I A Hughes, Prof. A E Edwards, and Dr S F Ahmed for their helpful comments.
Arch Dis Child 2005;90:991-992.

doi: 10.1136/adc. 2005.081968

Correspondence to: Prof. L T Weaver, Child Health Division of Developmental Medicine, Yorkhill Hospitals, Glasgow G3 8SJ, UK; Iweaver@clinmed.gla.ac.uk

Competing interests: none declared

\section{REFERENCES}

1 Anon. UK paediatric clinical research under threat. Arch Dis Child 1997:76:1-8.

2 Levene M, Olver R. A survey of clinical academic staffing in paediatrics and child health in the UK. Arch Dis Child 2005;90:450-3.

3 Weaver LT. The child is father of the man: paediatricians be more interested in adult disease. Clin Med 2001;1:38-43.

4 Weaver LT. A good doctor and/or a good scientist? The medical academic's mid-life crisis. $J$ S Soc Med 1993;27:444-6.

5 Academy of Medical Sciences. www.academicsci.ac.uk.

6 UK Clinical Research Collaboration. Modernising medical careers. NHS. 2005.

7 Savill J. Academic paediatrics: Easter Island or Easter Sunday? Arch Dis Child 2005;90:441.
Japanese children with cystic fibrosis. Just as the pattern of mutations varies throughout Caucasian societies, especially as one moves from the Mediterranean to Northern Europe, similar variations appear to be present in different Asian societies.

$\mathrm{Wu}$ and colleagues ${ }^{5}$ found that the frequency of CFTR mutant alleles in Taiwanese men with congenital bilateral absence of the vas deferens (CBAVD) was 36\%, lower than published frequencies in other ethnic CBAVD patients (ranging from $50 \%$ to $74 \%$ ).As well the mutation spectrum of CFTR in CBAVD patients did not overlap with the Caucasian CFTR mutation spectrum in this condition.

The environmental impact on phenotypic expression can relate to social factors such as recognition affecting the age of diagnosis, access to medical care, compliance with recommended care, and relative social disadvantage, especially in migrant communities.

Gene expression can be influenced more directly by epigenetic factors such as diet and toxins or by epigenetic inheritance of modifier genes co-inherited with the candidate gene. Promoter sequences elsewhere in the genes, independent of CFTR, may exert considerable influence on the outcomes of CF. However, a definitive modifier gene for CF remains to be identified. ${ }^{6}$ The expression of particular alleles in other conditions may also be influenced by whether the particular allele was inherited from the father or the mother and this may even be applicable to CF. ${ }^{7}$ 
The impact of gender of the affected child is clearly another important factor to consider as reported in the paper by Callaghan and colleagues. ${ }^{1}$ Kuhni and Sennhauser $^{8}$ have reported that the Yentl syndrome is alive and well with under-diagnosis and under-treatment in Swiss girls with asthma. Gee and colleagues $^{9}$ have found differences in attitude by children to their cystic fibrosis between girls and boys, with the girls' perceptions relating better to test results but poorer with respect to body image.

Another important perspective to consider is the best descriptor and predictor of disease severity and outcome. Most reports analyse outcomes individually on lung function, somatic growth, or sputum culture results. Liou and colleagues ${ }^{10}$ have argued that a multivariate model including age, gender, BMI, lung function, pancreatic insufficiency, diabetes mellitus, sputum cultures, and number of acute exacerbations provides a rigorous tool for clinical practice and research. This type of model may well better help us define accurately the phenotype to assist in the investigation of the environmental and epigenetic factors that impact on the expression of the various polymorphisms of the CFTR. Identification of these factors can only lead to improvement in outcome by better targeting therapeutic interventions.

Arch Dis Child 2005;90:992-993.

doi: 10.1136/adc.2005.079863

Correspondence to: Prof. L Landau, Professor of Paediatrics, The University of Western Australia, Perth, Western Australia; Ilandau@ cyllene.uwa.edu.au

Competing interests: none declared

\section{REFERENCES}

1 Callaghan BD, Hoo AF, Dinwiddie R, et al Growth and lung function in Asian patients with cystic fibrosis. Arch Dis Child 2005;90:1029-32.

2 Bowler IM, Estlin EJ, Littlewood JM. Cystic fibrosis in Asians. Arch Dis Child 1993;68:120-2.
3 Kabra SK, Kabra M, Lodha R, et al. Clinical profile and frequency of delta F508 mutation in Indian children with cystic fibrosis. Indian Pediatrics 2003:40:612-19.

4 Wang W, Okayama H, Shirato K. Genotypes of cystic fibrosis (CF) reported in the world and polymorphisms of the cystic fibrosis transmembrane conductance regulator (CFTR) gene [in Japanese]. Nippon Rinsho 1996;54:525-32.

5 Wu CC, Alper OM, Lu JF, et al. Mutation spectrum of the CFTR gene in Taiwanese patients with congenital bilateral absence of the vas deferens. Hum Reprod. In press.

6 Davies JC, Griesenbach U, Alton E. Modifier genes in cystic fibrosis. Pediatr Pulmonol 2005;39:383-91.

7 Wilkins JF. Genomic imprinting and methylation: epigenetic canalization and conflict. Trends Genet 2005;21:356-65.

8 Kuhni CE, Sennhauser FH. The Yentl syndrome in childhood asthma: risk factors for undertreatment of Swiss children. Pediatr Pulmonol 1995; 19:156-60.

9 Gee L, Abbott J, Conway SP, et al. Quality of life in cystic fibrosis: the impact of gender, general health perceptions and disease severity. I Cystic Fibrosis 2003;2:206-13.

10 Liou TG, Adler FR, Fitzimmons SC, et al. Predictive 5-year survivorship model of cystic fibrosis. Am J Epidemiol 2001;153:345-52

\section{How reliable are SIDS rates? The importance of a standardised, multiprofessional approach to "diagnosis"}

\section{P J Fleming, P S Blair}

Commentary on the paper by Sheehan et al (see page 1082)

\footnotetext{
A $s$ a "diagnosis", sudden infant death syndrome (SIDS) is unique in that the definition is reached by exclusion: by failing to show an adequate cause of death. The "diagnosis" of SIDS is inevitably subjective and imprecise as it depends on the knowledge, skill, and thoroughness of the professionals who obtain the clinical history, conduct the evaluation of the circumstances of the death, and perform the postmortem examination, as well as the synthesis and interpretation of this information.

Even if each of these component parts of the investigation have been conducted to a specified standard, the collection of this information is not the end point but should be the starting point for a multidisciplinary review process in which the professionals
}

involved should jointly examine the evidence, highlight concerns, and decide on the cause of death. This multidisciplinary approach has been used effectively in the field of SIDS research, ${ }^{1}$ has been shown to work in clinical practice, ${ }^{2}$ and has recently been recommended by the Kennedy Report ${ }^{3}$ as the routine national approach in the UK. Once the postmortem results are available, usually 8-12 weeks after death, the paediatrician, pathologist, GP, health visitor, senior investigating police officer, and where appropriate, social worker, should meet to discuss the case.

Sheehan and her colleagues ${ }^{4}$ have unambiguously shown how published SIDS rates become a mockery if a clear distinction is not made between contributory factors and what constitutes a sufficient explanation of death.
Unfortunately the hypothetical exercise they show here has already become a reality in England and Wales. From 1996 to 2003, Office for National Statistic (ONS) figures suggest the rate for unascertained deaths has risen more than fivefold to 0.2 deaths per 1000 live births in a period when the SIDS rate has dropped by 0.35 deaths per 1000 live births. The potential of a diagnostic transfer has not been ruled out by the ONS. ${ }^{5}{ }^{6}$ A recent survey of over 60 UK pathologists currently conducting SIDS postmortem examinations by Limerick and Bacon $^{7}$ suggests a growing reluctance to diagnose SIDS when the death occurs while sharing the parental bed or when a suspicious history is presented such as parental drug and alcohol abuse, previous unexplained illness, or age and time of death "not typical" of SIDS. Clearly the decision on what constitutes a sufficient explanation of death is not an easy one to make and there is a need, in some cases, to highlight salient features that may be contributory or even fully explain a death. However this decision is not one the pathologist should be asked to make alone or without the required guidance. Most infants who bed-share or live with parents who have a problem with alcohol or drugs are still alive the next morning, while "typical" characteristics of SIDS are changing, as rates fall. ${ }^{1}$ General practitioners, health visitors, paediatricians, and child protection teams with broad experience of normal childcare practices in their communities are less likely to attribute death or injury to normal variants in patterns of 
childcare. A multidisciplinary team is needed to diagnose SIDS and requires a standardised classification system that highlights concerns but gives guidelines on what constitutes a full explanation of death.

In Avon we have been developing such a classification system over the past 20 years. ${ }^{128-10}$ It is based on a simple grid system, one axis representing the three components of the definition of SIDS (the history, the death scene examination, and the pathology), the other axis representing an incremental scale towards the explanation of death, with gradation between the completely inexplicable sudden death (classification Ia) and the fully explained (III). This system allows for notable factors to be identified (classification Ib); for instance, the fact an infant was put down prone to sleep or co-slept in the parental bed. This system also allows for factors that possibly contributed to the death (IIa), such as sleeping prone while heavily wrapped or co-sleeping under an adult duvet, and factors that probably contributed to the death (IIb) such as sleeping prone while heavily wrapped with an infection or cosleeping under an adult duvet with an adult who had consumed a lot of alcohol. The overall classification of death is taken as the highest classification given among the three investigative components of SIDS. Note this is not a diagnostic system; all of these deaths are still SIDS as none of these factors on their own are sufficient to fully explain the death. Nor is this an attempt to redefine SIDS; all we are doing is trying to put into words our thought processes on the shade of grey, to quantify our degree of uncertainty between the inexplicable and explained. The presence of a finding that on its own gives a complete and sufficient explanation of the death (for example, meningococcal septicaemia) takes the diagnosis out of the field of SIDS, but there may still be important contributory factors to the death that have implications for future care of the family and the quality of care in the community. ${ }^{2} 910$

A multidisciplinary case discussion meeting is more than just reaching a consensus of opinion about the death. The meeting is for sharing information and future care planning for the family. It is important that there is an explicit discussion of the possibility of neglect or abuse as a contributory factor to the infant's death, but equally the quality of the medical and social care given should also be discussed at the meeting, identifying any shortcomings and appropriate measures to improve future care.

The international acceptance of SIDS as an entity in 1969 was an admission, perhaps a courageous one, that we were ignorant as to the cause of such deaths but aware of the profound effect on our infant mortality rates. By careful study we have substantially reduced the numbers, yet still do not fully understand why these infants die. Perhaps we need to be more courageous in our admission of ignorance, or at least distinguish between probable contribution and explanation when assigning the cause of death.

Arch Dis Child 2005;90:993-994.

doi: 10.1136/adc.2005.073122

\section{Authors' affiliations}

P J Fleming, P S Blair, Institute of Child Life and Health, University of Bristol, UK

Correspondence to: Prof. P Fleming, Institute of Child Life and Health, UBHT Education Centre, Upper Maudlin St, Bristol BS2 8AE, UK; peter. fleming@bris.ac.uk

Competing interests: Both authors were principal investigators in the CESDI SUDI studies, and have been involved in the development and publication of the Avon multiprofessional approach to the investigation of SUDI. ${ }^{2}$ PJF was a member of the Kennedy Committee. ${ }^{3}$

\section{REFERENCES}

1 Fleming PJ, Blair P, Bacon C, et al. Sudden unexpected deaths in infancy. The CESDI SUDI Studies 1993-1996. London: The Stationery Office, 2000:112.

2 Fleming PJ, Blair PS, Sidebotham P, et al. Investigating sudden unexpected deaths in infancy and childhood and caring for bereaved families: an integrated multiagency approach. BMJ 2004;328:331-4.

3 Kennedy Report. Sudden unexpected death in infancy. The report of a working group convened by the Royal College of Pathologists and the Royal College of Paediatrics and Child Health, Sept 2004. www.rcpath.org or www.rcpch.ac.uk.

4 Sheehan KM, McGarvey C, Devaney DM, et al. How reliable are SIDS rates? Arch Dis Child 2005;90:1082-3.

5 Office for National Statistics. Trends in cot death. Health Statistics Quarterly 2000;05:17-25.

6 Office for National Statistics. Are unascertained deaths the same as sudden infant deaths? Health Statistics Quarterly 2001;10:20-4.

7 Limerick SR, Bacon CJ. Terminology used by pathologists in reporting on sudden infant deaths. J Clin Pathol 2004:57:309-11.

8 Gilbert R, Rudd P, Berry J, et al. Combined effects of infection and heavy wrapping on the risk of sudden unexpected infant death. Arch Dis Child 1992;67:171-7.

9 Leach CEA, Blair PS, Fleming PJ, et al. Sudden unexpected deaths in infancy: similarities and differences in the epidemiology of SIDS and explained deaths. Pediatrics 1999;104(4):e43

10 Blair PS, Fleming PJ. Commentary on the article "Evaluation of circumstances and clinical history of SUDI". Scandinavian Journal of Forensic Sciences 2004;3:80.

\section{Perspectives on the development of an international consensus on childhood obesity}

\section{C J Rudolf, Z Hochberg, P Speiser}

\section{A discussion of the recent International Consensus Statement}

l: March 2005 an important document was published in the Journal of Clinical Endocrinology and Metabolism. ${ }^{1}$ It resulted from a meeting held at the Dead Sea in Israel 12 months previously where experts were invited to contribute to the development of a consensus on the widespread crisis in childhood obesity. The group consisted of 65 physicians and other health professionals representing nine countries on four continents. Their aim was to explore the available evidence on childhood obesity and develop a consensus as to the way forward.

The process was rigorous. In the months prior to meeting, participants were assigned to groups addressing prevalence, causes, risks, prevention, diagnosis, treatment, or psychology. Each group communicated electronically, selected key issues for their area, searched the literature, and developed a draft document. So, before they had even met, each group had drawn together their views based on the evidence available. Over the three day meeting every paragraph of these papers were debated, finalised, and signed, initially by each group, and then by the full meeting.

The result is an impressive document where the evidence is summarised, and recommendations developed. Given the 
Table 1 Summary of recommendations from the consensus development: childhood obesity

\begin{tabular}{ll}
\hline Recommendations \\
\hline $\begin{array}{l}\text { Definitions } \\
\text { BMI }>95 \text { th centile on national charts ( } 98 \text { th centile on UK charts) for clinical purposes, BMI }>85 \text { th centile for overweight } \\
\text { IOTF cut offs for epidemiological purposes and international comparison }\end{array}$ \\
$\begin{array}{l}\text { Pction is required antenatally, in schools, community facilities, marketing, government, and regulatory agencies } \\
\text { Screening }\end{array}$ \\
$\begin{array}{l}\text { Population screening is required to identify children with BMI }>85 \text { th centile } \\
\text { Assessment }\end{array}$ \\
$\begin{array}{l}\text { Laboratory assessment of children with BMI }>95 \text { th centile should include: } \\
\text { Thyroid and liver function tests, fasting glucose, insulin, and lipid profile } \\
\text { Periodic oral glucose tolerance tests from age } 10 \text { for those at increased risk of the metabolic syndrome } \\
\text { Screening for other comorbidities, e.g. hypertension, sleep apnoea, orthopaedic problems, etc }\end{array}$ \\
Children with BMI $>85$ th centile should receive regular lifestyle counselling \\
Children with BMI $>95$ th centile require specialist paediatric care \\
Children with comorbidity or severe obesity should receive their care in a multidisciplinary specialist service
\end{tabular}

importance and prevalence of childhood obesity, there is a remarkable lack of quality evidence, ${ }^{2}$ so a consensus of experts is a good starting point. The aim of the meeting was to provide a platform directed at future corrective action and to foster ongoing debate in the international community. This was achieved.

The strength of the Statement lies in its clear and succinct review of the evidence. Areas that are covered well include methods for assessing body fat and its distribution, the definition of overweight and obesity, the genetic determinants of obesity, endocrine aspects, psychosocial determinants, metabolic risks, and intervention. The section on treatment is particularly helpful, giving the rationale for intervening early, followed by the research evidence for diet and physical activity, as well as initial evidence for pharmacological and surgical treatments.

The mood of the meeting was positive and assertive. Full debate took place in small groups and in the larger forum, but by the close, there was agreement on a number of recommendations. These are summarised in table 1 and principally relate to:

- The definition of obesity and overweight

- The need for screening

- Assessment of children who are already obese

- Treatment and services

\section{HOW SHOULD WE DEFINE OBESITY?}

The definition of obesity requires a simple, low cost, accurate, and reproducible measure of fat mass, with relation to the risk of morbidity. Body mass index is far from ideal, but is clearly the only feasible clinical measure, although waist circumference, as a surrogate measure of visceral fat, also received attention because of its association with increased cardiovascular risk in adults.

Recommendations (see table 1) regarding definitions of obesity were based on the epidemiological evidence that impaired glucose intolerance, hypertension, triglycerides, C-reactive protein, and interleukin-6 concentrations all increase significantly when BMI is above the 95th centile. ${ }^{1}$ Even a BMI between the 85th and 95th centiles places children at increased risk, whereas metabolic disturbances are rare when BMI is below the 85th centile.

The International Obesity Task Force (IOTF) criteria were also discussed. These are based on adult cut-offs, modified for children. ${ }^{3}$ IOTF centile charts do not exist so they are not suitable for clinically monitoring, but they were supported for epidemiological use and international comparisons.

\section{THE NEED FOR SCREENING AND ASSESSMENT}

On the basis of metabolic risk, the meeting recommended that routine identification of obesity should be instituted in order to target lifestyle advice for those who are overweight and treatment for those who are obese. It went on to recommend that children above the high-risk cut-off should be screened for hypertension, sleep apnoea, thyroid and liver function tests, glucose impairment, lipid profile, and orthopaedic problems. Children at higher risk for the metabolic syndrome require full oral glucose tolerance tests, to be repeated periodically from the age of 10 .

\section{TREATMENT AND SERVICES}

The arguments for intervening early are made forcefully and go beyond the fact that excessive weight gain in childhood increases the risks of adult obesity and its consequences: childhood obesity in and of itself adds to the risks of adult obesity beyond its tracking into adulthood; early vascular lesions are detectable in obese children as young as 3 , suggesting that atherogenesis can begin in childhood; severe obesity in very young children already has its complications in terms of sleep apnoea and orthopaedic anomalies; and it is becoming increasingly apparent that glucose intolerance, type 2 diabetes, dyslipidaemia, and hypertension frequently have their onset before puberty. The point is made well therefore that good medical reasons exist for developing paediatric services rather than delaying care until adulthood. There was also some optimism that intervention at a younger age may be more successful and beneficial than treatment of established, severe obesity in adolescence or adulthood.

The Statement emphasises the central role of lifestyle change in treatment, and also maps out the pharmacological options and surgery in special cases. It comes down clearly on the need for obese children to receive specialist care, and for those with morbid obesity to be cared for by a multidisciplinary team.

\section{IMPLICATIONS OF THE CONSENSUS FOR THE UK}

The UK has among the highest figures for childhood obesity in the Western world with figures currently at $15.5 \% .^{5}$ Encouragingly there is an increasing public awareness of the problem and some political will for action, but no real clarity as to what is required. I (MCJR) therefore feel fortunate that I was invited to take part in the Consensus process. I was left with much food for thought, and also concern that what we have to offer in the UK is far behind those of colleagues elsewhere. I have to admit too that I was troubled that there was a lack of focus on the cost 
consequences of implementing recommendations at a population level.

The recommendation regarding identification of obese children is very much at variance with the debate taking place in the UK where most paediatricians would argue that screening is inappropriate until we have effective treatment to offer. I suspect that this in part is due to the fact that most participants worked in healthcare systems where regular review of children was possible, and so would not incur substantial costs. We do need to consider in our debate that we have only focused on screening for obesity per se. Once we grasp the enormity of the degree of morbidity already present, we may need to think again, especially as treatment for morbidity may become available before we have found ways to effectively impact on lifestyle.

The recommendation that obese children are fully assessed for comorbidity has further huge implications and costs. Children referred to endocrine services probably have most of the identified tests, but those seen in primary or secondary care probably do not-another example of inequity in paediatric care.

The recommendations regarding treatment largely hinged on an attitude shared by the participants that patients benefited from the care they received, despite the lack of evidence for effective interventions from randomised controlled trials. ${ }^{2}$ It seemed that the majority saw that the apparent absence of evidence was not evidence of absence. This positive attitude was so distant from attitudes I encounter in the UK, that on my return I surveyed 18 community paediatric colleagues and was not surprised to find that the majority confirmed that they rated their care of obese children as being both ineffective and unrewarding.
Why do we have such a difference in attitude here? It may well relate to the difference in resources and settings in which we work. I polled the Consensus participants to find out the form that their services for obesity take. The majority responded that they worked within settings where dietary and psychological support were readily available, and most worked in the context of good multidisciplinary teams.

My participation in the Consensus meeting left me feeling that it was indeed possible to have an impact on the problem of childhood obesity. It no doubt requires energy and resources, but that with effort much could be achieved. That was a year ago!

Despite the House of Commons Health Select Committee's call on the NHS to ensure obese children have access to specialist care, ${ }^{4}$ progress is slow. Colleagues in the British Association of Community Child Health confirm that services are patchy across the country, with access to dietetic and psychological input often very limited with long waiting times, and few areas have specialist multidisciplinary teams. Our experience in Leeds is far from unique. We are struggling to find clinical or research support for a community obesity programme despite some promising results. The paediatric dietetic service accepts no referrals for obesity at all, and our specialist outpatient obesity clinic has no dietetic, psychology, or even nursing support, despite the increasing number of referrals for complex and very young children. Other agencies (Education and Leisure) are better resourced, but are providing initiatives that are not being properly evaluated. Leeds Leisure Services are even measuring BMI on all year 7 pupils in the city to identify obesity, but without reference to growth standards!

It seems that preventive measures are beginning to be put in place, universal monitoring is being discussed, but therapeutic services are lagging behind. If we are to achieve anything within this epidemic we need leadership and resources. This International Consensus Statement has provided a platform for debate and a direction for corrective action. It is worth reading for its review of the evidence and its conclusions. We hope it will stimulate fresh debate as to a way forward and the provision of enough resources that we can begin to provide adequate care for children suffering from obesity and its consequences.

Arch Dis Child 2005;90:994-996.

doi: $10.1136 /$ adc. 2005.075762

\section{Authors' affiliations}

M C J Rudolf, Leeds University, UK

Z Hochberg, Meyer Children's Hospital, Israel

P Speiser, Schneider Children's Hospital, USA

Correspondence to: Prof. M Rudolf, Community Paediatrics, Belmont House, 3-5 Belmont Grove, Leeds LS17 8DR, UK; mary.rudolf@ leedsth.nhs.uk

Competing interests: none declared

\section{REFERENCES}

1 Speiser $\mathbf{P}$, Rudolf $M C J$, Anhalt $\mathrm{H}$, et al. Consensus statement: childhood obesity. J Clin Encocrinol Metab 2005:90:1871-87.

2 Summerbell CD, Ashton V, Campbell KJ, et al. Interventions for treating obesity in children (Cochrane Review). In: The Cochrane Library, Issue 1. Chichester: John Wiley and Sons Ltd, 2004.

3 Cole TJ, Bellizzi MC, Flegal KM, et al. Establishing a standard definition for child overweight and obesity worldwide: international survey. BMJ 2000;320:1240-3.

4 Rudolf MCJ. The obese child. Arch Dis Child Educ Pract Ed 2004;89:ep57-62.

5 Department of Health. White Paper. Choosing health: making healthier choices easier. DoH, November 2004 